\title{
Comparison of capillary and arterial blood gas measurements in neonates
}

\author{
B I MCLAIN, J EVANS, AND P R F DEAR \\ Department of Paediatrics and Child Health, University of Leeds, St James's University Hospital, Leeds
}

SUMMARY One hundred and fifty eight paired arterial and capillary blood samples were obtained from 41 sick preterm infants in their first week of life and the $\mathrm{pH}$, and $\mathrm{PCO}_{2}$, and $\mathrm{PO}_{2}$ concentrations were measured. Half of the capillary samples were obtained from unwarmed heels and half from heels warmed to $40^{\circ} \mathrm{C}$. A potentially significant discrepancy (arbitrarily defined as 0.05 units for $\mathrm{pH}, 1 \mathrm{kPa}$ for $\mathrm{PCO}_{2}$, and $3 \mathrm{kPa}$ for $\left.\mathrm{PO}_{2}\right)$ was found in $19(24 \%)$ of cases for $\mathrm{pH}$, in $9(11 \%)$ for $\mathrm{PCO}_{2}$ and in $21(26 \%)$ for $\mathrm{PO}_{2}$. Warming the heel produced no significant improvement in results. We conclude that capillary blood provides satisfactory measurements of $\mathrm{pH}$ and $\mathrm{PCO}_{2}$ for all but the most critical purposes, but that the usefulness of capillary $\mathrm{PO}_{2}$ estimations is limited to the exclusion of hypoxia.

Blood gas analysis is often performed for neonates on blood samples taken either from arteries or capillaries, but there have been few publications comparing the results obtained from these two sources in babies. Studies by Gandy et al in babies weighing over $2000 \mathrm{~g}$ at birth, ${ }^{1}$ and by Koch et al, ${ }^{2}$ and MacRae et $a^{3}$ in healthy term babies, showed that the $\mathrm{pH}$ and $\mathrm{PCO}_{2}$ measurements of arterial and capillary blood collected from warmed heels were similar after the first few hours of life. Arterial and capillary $\mathrm{PO}_{2}$ measurements showed a less strong association. Gandy et $a l^{1}$ found a poor correlation, and Glascow et $a l^{4}$ and Usher ${ }^{5}$ found that the correlation was reasonable only when the arterial $\mathrm{PO}_{2}$ was below $8 \mathrm{kPa}$. Winquist et al, ${ }^{6}$ using histamine iontophoresis to arterialise capillary blood, showed a close correlation in preterm babies over 5 days old, and Corbett et $a l^{7}$ and Desai et $a l^{8}$ described a good correlation between arterial and capillary $\mathrm{PO}_{2}$ using the dorsal surfaces of the finger and the scalp, respectively, as the sources of capillary blood.

In only one of the publications cited ${ }^{6}$ were ill preterm babies studied; and that was in 1970 when babies in the neonatal intensive care unit were considerably more mature than they are today. We therefore felt that an up to date investigation of the association between arterial and capillary blood gas measurements was warranted.

A questionnaire sent to 42 neonatal units showed that more than half relied on capillary samples for most of their blood gas estimations. One third of the units attempted to warm the site from which the blood was taken before sampling. Twenty nine of the respondents thought that capillary $\mathrm{PO}_{2}$ measurement was of no value, 11 thought that it was reliably 2-3 $\mathrm{kPa}$ below the arterial value, and two thought that it accurately reflected the arterial $\mathrm{PO}_{2}$. The present study was designed to compare capillary blood gases taken from unwarmed heels and from heels warmed to $40^{\circ} \mathrm{C}$ with arterial gases to find out whether the capillary measurements were sufficiently accurate to be used in clinical practice.

\section{Patients and methods}

One hundred and fifty eight paired arterial and capillary blood samples were obtained from 41 preterm babies, median gestational age 30 weeks (range 23-34). All were between 3 hours and 7 days old and had indwelling umbilical arterial catheters. At the time of sampling each baby had a normal central temperature $\left(36 \cdot 8^{\circ}-37 \cdot 2^{\circ} \mathrm{C}\right)$ and a mean arterial blood pressure above $30 \mathrm{~mm} \mathrm{Hg}$. Thirty five of the babies had respiratory distress syndrome, and $57 \%$ were receiving muscle relaxants at the time of sampling. All capillary samples were obtained when capillary puncture was performed for Dextrostix measurement-this is routine practice as our arterial lines are perfused with dextrose. The study was approved by the local ethical committee.

The first pair of samples from each infant comprised an arterial sample and a capillary sample taken simultaneously from an unwarmed heel 
(group 1). The second pair comprised an arterial sample and a capillary sample taken simultaneously from a heel warmed in water at $40^{\circ} \mathrm{C}$ for five minutes before sampling (group 2). The capillary samples were taken from the medial and lateral borders of the heel using an Autolet; a $200 \mu \mathrm{l}$ sample of blood was collected into a heparinised tube. Arterial samples were collected after a $2 \mathrm{ml}$ 'dead space' volume had been removed from the line. All samples were analysed on a Radiometer ABL 300 blood gas analyser within five minutes of being taken. The machine's precision was tested by analysing 10 consecutive samples from the same source. The standard deviations for $\mathrm{pH}, \mathrm{PCO}_{2}$ and $\mathrm{PO}_{2}$ were $0 \cdot 001,0.04 \mathrm{kPa}$, and $0.3 \mathrm{kPa}$, respectively.

Confidence intervals are reported for the data that approximated to a normal distribution. The results for $\mathrm{PO}_{2}$ have a skewed distribution and were analysed by Kendall's $S$ test, a non-parametric, distribution free method.

\section{Results}

Seventy nine paired samples were obtained for each group. For each of the measured variables we studied the distribution of arterial and capillary measurements, the distribution of the differences between paired arterial and capillary measurements (referred to as 'discrepancies'), and the proportion of results in which it was thought that the discrepancy was of potential clinical importance, $(0.05$ units of $\mathrm{pH}, 1 \mathrm{kPa}$ for $\mathrm{PCO}_{2}$, and 1,2 , and $3 \mathrm{kPa}$ for $\mathrm{PO}_{2}$ ).

The distribution of $\mathrm{pH}$ measurements is shown in fig 1 and the discrepancies between arterial and capillary measurements in table 1 . There was no significant difference in mean discrepancy between the two groups $(95 \%$ confidence intervals -0.006 to +0.014 units; the $5 \%$ significance figure of +0.004 lies within this interval). This suggests that warming the heel had little beneficial effect on $\mathrm{pH}$ measurement. Overall, 28 of $158(18 \%)$ of the paired samples were discrepant by more than 0.05 units of $\mathrm{pH}$ (that is, about a $12 \%$ difference in hydrogen ion concentration).

Table 1 Discrepancy between arterial and capillary $p H$ measurements in paired samples taken from unwarmed heels (group 1) and warmed heels (group 2)

\begin{tabular}{lll}
\hline & $\begin{array}{l}\text { Group } 1 \\
(n=79)\end{array}$ & $\begin{array}{l}\text { Group 2 } \\
(n=79)\end{array}$ \\
\hline $\begin{array}{l}\text { Mean (SD) discrepancy } \\
(\text { arterial minus capillary value })\end{array}$ & $0.005(0 \cdot 035)$ & $0.001(0 \cdot 033)$ \\
$\begin{array}{l}95 \% \text { confidence intervals } \\
\text { No }(\%) \text { of results in which } \\
\text { discrepancy exceeded } \\
0.05 \text { units }\end{array}$ & -0.06 to $0 \cdot 07$ & -0.06 to 0.07 \\
& $19(24)$ & $9(11)$ \\
\hline
\end{tabular}

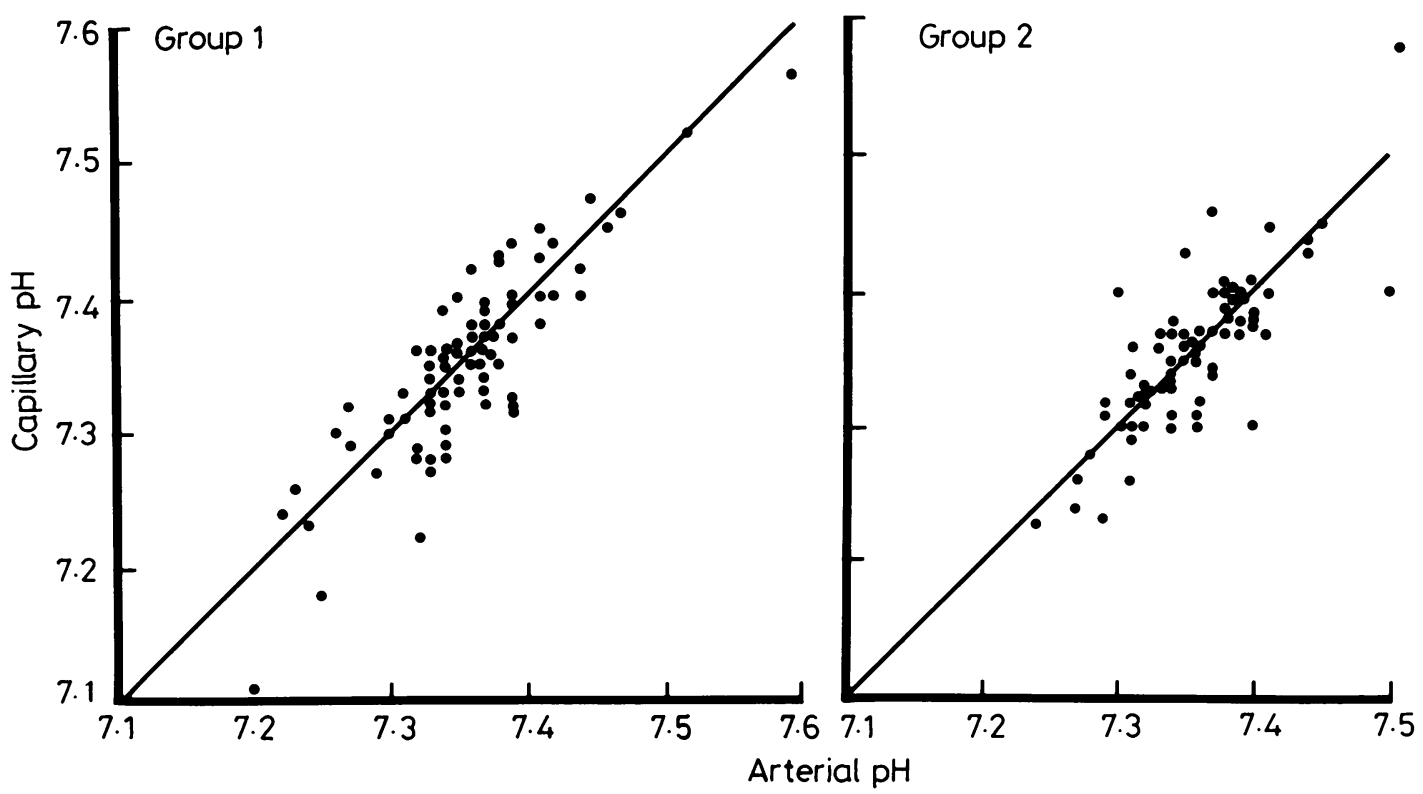

Fig 1 pH of arterial and capillary blood in paired samples taken from unwarmed heels (group l) and warmed heels (group 2) with line of identity. 


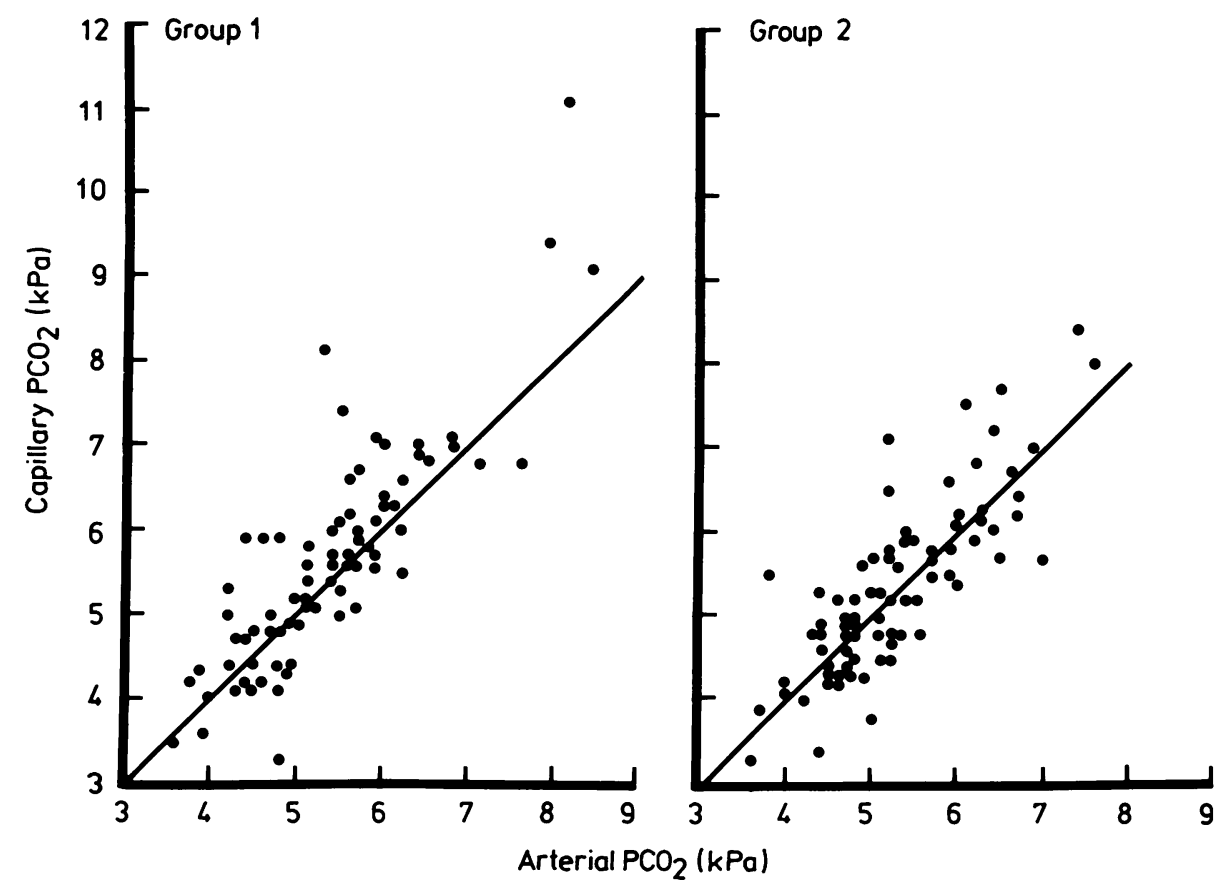

Fig $2 \mathrm{PCO}_{2}$ of arterial and capillary blood in paired samples taken from unwarmed heels (group 1) and warmed heels (group 2) with line of identity.

The distribution of $\mathrm{PCO}_{2}$ measurements is shown in fig 2 and the discrepancies between arterial and capillary measurements are shown in table 2 . The difference in the mean discrepancy between the two groups was not significant at the $5 \%$ level $(95 \%$ confidence intervals -1.1 to $+1.5 \mathrm{kPa}$; the $5 \%$ significance figure of -0.21 lies within this interval), indicating that warming the heel had little effect. Overall, 15 of $158(10 \%)$ of the paired samples were discrepant by more than $1 \mathrm{kPa}$.

The distribution of $\mathrm{PO}_{2}$ measurements is shown in fig 3 , and the discrepancies between arterial and

Table 2 Discrepancy between arterial and capillary $\mathrm{PCO}_{2}$ measurements in paired samples taken from unwarmed heels (group 1) and warmed heels (group 2)

\begin{tabular}{|c|c|c|}
\hline & $\begin{array}{l}\text { Group } 1 \\
(n=79)\end{array}$ & $\begin{array}{l}\text { Group } 2 \\
(n=79)\end{array}$ \\
\hline $\begin{array}{l}\text { Mean (SD) discrepancy } \\
\text { (arterial minus capillary valuc) }\end{array}$ & $\begin{array}{l}-0 \cdot 26 \mathrm{kPa} \\
(0 \cdot 7)\end{array}$ & $\begin{array}{l}-0 \cdot 05 \mathrm{kPa} \\
(0 \cdot 65)\end{array}$ \\
\hline $95 \%$ confidence intervals & $\begin{array}{l}-0.42 \text { to } \\
+0.1 \mathrm{kPa}\end{array}$ & $\begin{array}{l}-0.18 \text { to } \\
+0.08 \mathrm{kPa}\end{array}$ \\
\hline $\begin{array}{l}\text { No }(\%) \text { of results in which } \\
\text { discrepancy exceeded } \\
1 \mathrm{kPa}\end{array}$ & $9(11)$ & $6(8)$ \\
\hline
\end{tabular}

capillary measurements in table 3 and fig 4 . A comparison of the discrepancies between the two groups showed no significant difference at the $5 \%$ level, again suggesting that warming the heel made little difference $(S=1036$; variance $(s)=3944$ and 312; SD $1 \cdot 8 ; \mathrm{p}>0 \cdot 1)$.

\section{Discussion}

The merits of sampling capillary blood for analysis of blood gases are that it is technically easier and less likely to result in serious complications than arterial catheterisation or puncture, and that sites are available when arterial sites are not, but it is a clinically useful technique only if the blood gas measurements obtained are a sufficiently accurate guide to the arterial measurements. In this study the arterial blood gas measurements were taken as the 'gold standard' by which capillary measurements were judged. To what extent the discrepancies reported are methodological (for example, diffusion of $\mathrm{CO}_{2}$ from capillary blood during sampling), or physiological is uncertain, but a standard capillary blood sampling procedure was used and more attention was probably paid to good technique than can usually be guaranteed, and so the study is 
746 McLain, Evans, and Dear

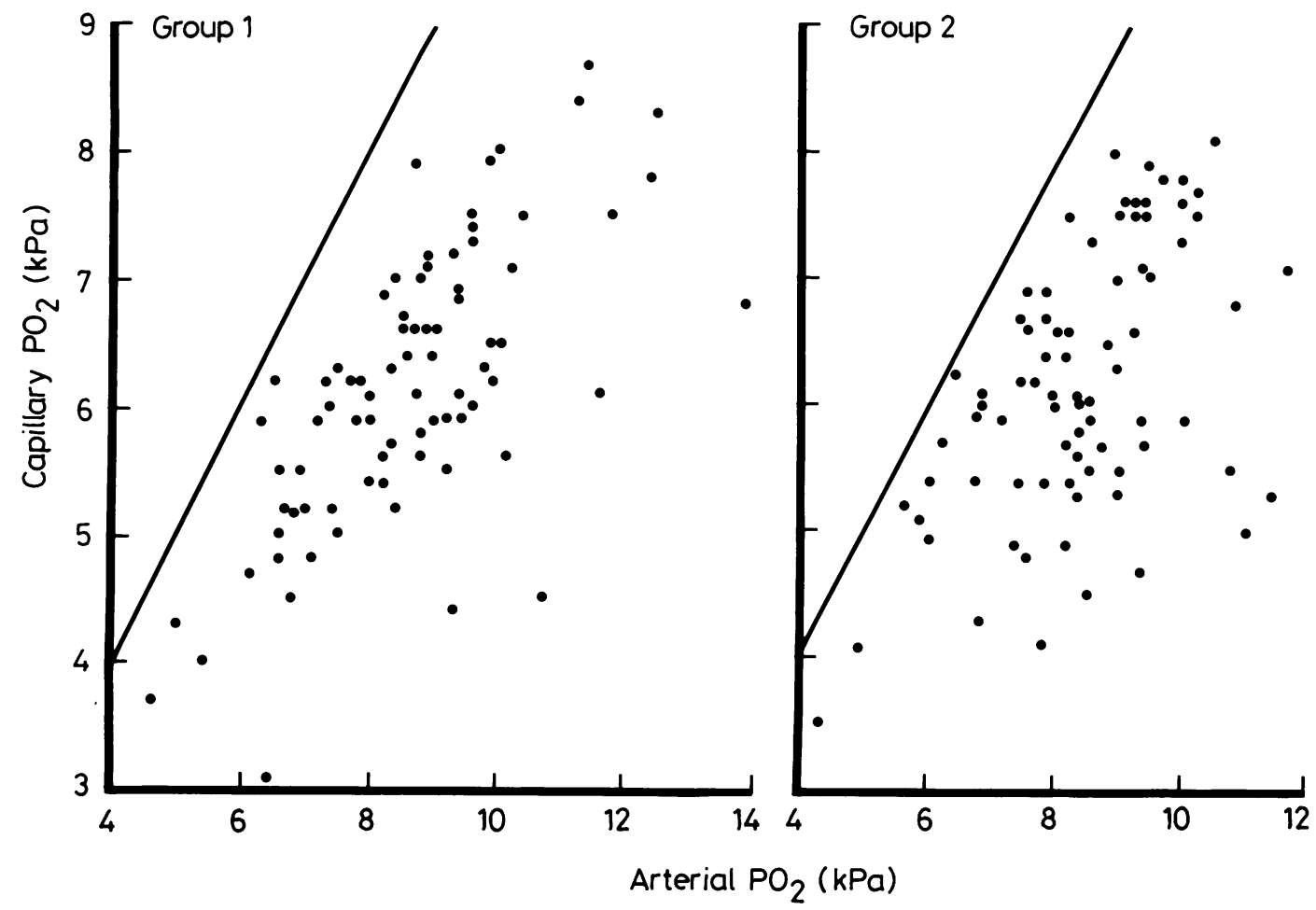

Fig $3 \mathrm{PO}_{2}$ of arterial and capillary blood in paired samples taken from unwarmed heels (group I) and warmed heels (group 2) with line of identity.

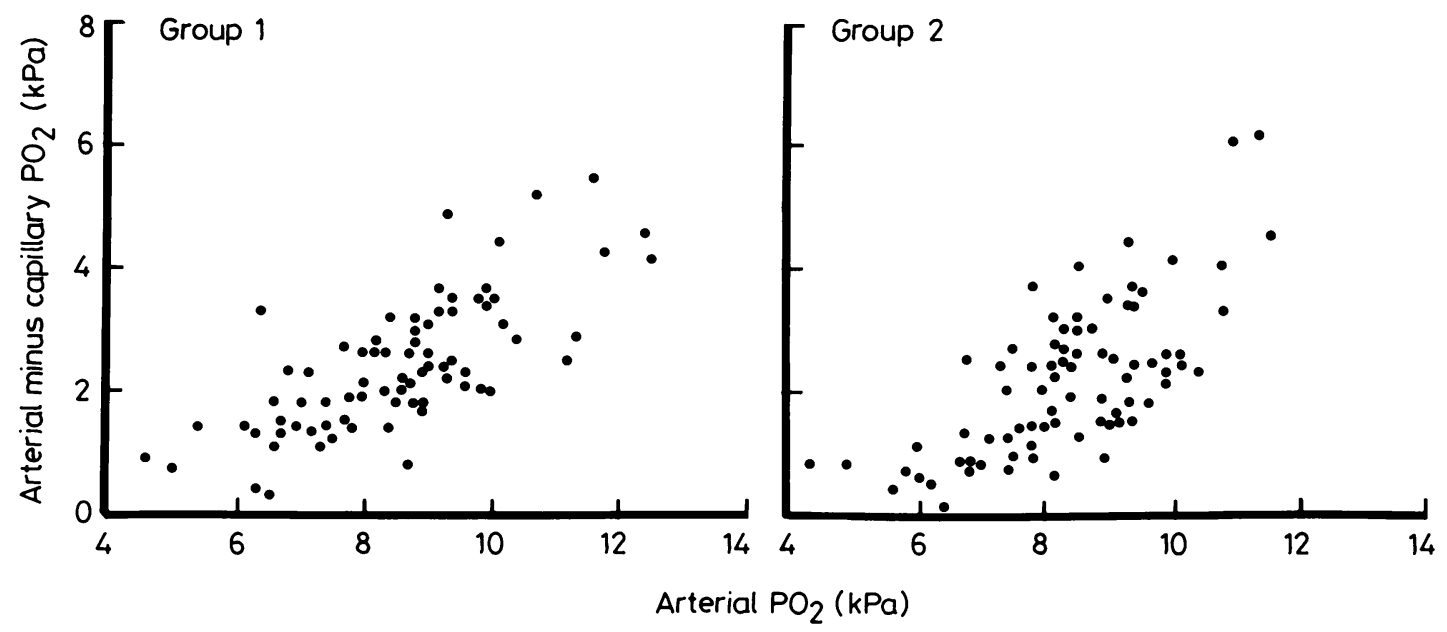

Fig 4 Discrepancy between arterial and capillary $\mathrm{PO}_{2}$ measurements in samples taken from unwarmed heels (group I) and warmed heels (group 2) and arterial $\mathrm{PO}_{2}$ measurements in the two groups. 
Table 3 Discrepancy between arterial and capillary $\mathrm{PO}_{2}$ measurements in paired samples taken from unwarmed heels (group 1) and warmed heels (group 2)

\begin{tabular}{lll}
\hline & $\begin{array}{l}\text { Group } ~ \\
(n=79)\end{array}$ & $\begin{array}{l}\text { Group } 2 \\
(n=79)\end{array}$ \\
\hline $\begin{array}{l}\text { Mean (SD) discrepancy } \\
\text { (artcrial minus capillary value) }\end{array}$ & $\begin{array}{l}2.47 \mathrm{kPa} \\
(1 \cdot 20)\end{array}$ & $\begin{array}{c}2 \cdot 17 \mathrm{kPa} \\
(1.25)\end{array}$ \\
$\begin{array}{l}\text { Range } \\
\text { No (\%) of results in which }\end{array}$ & 0.3 to $7 \cdot 2 \mathrm{kPa}$ & $0 \cdot 1$ to $6 \cdot 1 \mathrm{kPa}$ \\
discrepancy exceeded: & & \\
$1 \mathrm{kPa}$ & $74(94)$ & $59(75)$ \\
$2 \mathrm{kPa}$ & $47(59)$ & $42(53)$ \\
$3 \mathrm{kPa}$ & $21(27)$ & $16(20)$ \\
\hline
\end{tabular}

representative of what happens in practice. It is unlikely that a consensus could be reached among paediatricians as to what is a 'sufficiently accurate' guide to arterial measurements, and undoubtedly this also depends on the state of the patient. From the results of this study we contend that in acutely ill preterm babies, for whom no effort is spared to maintain meticulous homoeostasis, capillary blood analysis may not reflect any arterial blood gas variable with sufficient accuracy.

In less critical circumstances the measurements of $\mathrm{pH}$ and $\mathrm{PCO}_{2}$ derived from capillary blood were satisfactory, but there is limited clinical usefulness in the association between arterial and capillary $\mathrm{PO}_{2}$ measurements. The tendency for the discrepancy in $\mathrm{PO}_{2}$ to diminish as lower figures were approached, and the fact that capillary $\mathrm{PO}_{2}$ never exceeded arterial $\mathrm{PO}_{2}$, confers some value on capillary blood gas analysis as a means of excluding hypoxia. Hyperoxia, on the other hand, is difficult to exclude by capillary blood gas analysis. It is tempting to interpret fig 3 as suggesting that arterial $\mathrm{PO}_{2}$ measurements above $11 \mathrm{kPa}$ are unlikely as long as the capillary $\mathrm{PO}_{2}$ is kept below about $6 \mathrm{kPa}$, but this is to extrapolate beyond the limits of the data as there are not enough babies with excessively high arterial $\mathrm{PO}_{2}$ measurements to support this conclusion.

In this study warming the heel made no significant difference to the discrepancy between arterial and capillary measurements of any of the variables. It may be that temperatures above $40^{\circ} \mathrm{C}$ would be more effective in arterialising capillary blood, but we were concerned about the possibility of damaging the skin.

\section{References}

' Gandy G, Grann L. Cunningham N. The validity of $\mathrm{pH}$ and $\mathrm{pCO}_{2}$ measurements in sick and healthy newborn infants. Pediatrics 1964:34:192-7.

2 Koch G, Wendel $\mathrm{H}$. Comparison of $\mathrm{pH}$, carbon dioxide tension, standard bicarbonate and oxygen tension in arterial and capillary blood in the newborn period. Acta Paediatr Scand 1967;56: $10-16$.

${ }^{3}$ MacRae OJ, Pulavradji O. Comparison between arterial, capillary and venous acid base measurements in the newborn infant. Journal of Obstetrics and Gynaecology of the British Commonwealth 1966;75:761-5.

4 Glascow JFT, Flynn DM, Swyer PR. A comparison of descending aortic and arterialised capillary blood in the sick neonate. Can Med Assoc J 1972;106:660-3.

${ }^{5}$ Usher R. Discussion of complications arising from catheterisation of umbilical vessels. In: Lucey JF, ed. Problems of neonatal intensive care. A report of the 59th Ross Conference of Paediatric Research. New York: Columbus Press, 1969:36-43.

6 Winquist RA, Stamm SJ. Arterialised capillary sampling using histamine iontophoresis. J Pediatr 1970;76:455-8.

7 Corbett AJS, Burnard ED. Oxygen tension measurements on digital blood in the newborn. Pediatrics 1970;46:780-2.

${ }^{8}$ Desai JD, Holloway R, Thambiran AK. A comparison between arterial and arterialised capillary blood in infant. $S$ Afr Med $J$ 1967;41:13-15.

Correspondence to Dr PRF Dear, Department of Paediatrics and Child Health, University of Leeds, St James's University Hospital, Leeds LS9 7TF.

Accepted 2 March 1988 